AperTO - Archivio Istituzionale Open Access dell'Università di Torino

\title{
Communal nesting in the garden dormouse (Eliomys quercinus)
}

\section{This is the author's manuscript}

Original Citation:

\section{Availability:}

This version is available http://hdl.handle.net/2318/1631366

since 2017-05-23T10:58:39Z

Published version:

DOI:10.1016/j.beproc.2016.11.016

Terms of use:

Open Access

Anyone can freely access the full text of works made available as "Open Access". Works made available under a Creative Commons license can be used according to the terms and conditions of said license. Use of all other works requires consent of the right holder (author or publisher) if not exempted from copyright protection by the applicable law. 
This Accepted Author Manuscript (AAM) is copyrighted and published by Elsevier. It is posted here by agreement between Elsevier and the University of Turin. Changes resulting from the publishing process - such as editing, corrections, structural formatting, and other quality control mechanisms - may not be reflected in this version of the text. The definitive version of the text was subsequently published in BEHAVIOURAL PROCESSES, 135, 2017, 10.1016/j.beproc.2016.11.016.

You may download, copy and otherwise use the AAM for non-commercial purposes provided that your license is limited by the following restrictions:

(1) You may use this AAM for non-commercial purposes only under the terms of the CC-BY-NC-ND license.

(2) The integrity of the work and identification of the author, copyright owner, and publisher must be preserved in any copy.

(3) You must attribute this AAM in the following format: Creative Commons BY-NC-ND license (http://creativecommons.org/licenses/by-nc-nd/4.0/deed.en), 10.1016/j.beproc.2016.11.016

The publisher's version is available at:

http://linkinghub.elsevier.com/retrieve/pii/S0376635716303734

When citing, please refer to the published version.

Link to this full text:

http://hdl.handle.net/ 


\title{
Behavioural Processes 135 (2017) 25-28
}

\section{Communal nesting in the garden dormouse (Eliomys quercinus)}

\author{
Adrià Viñals ${ }^{a,{ }^{*}}$, Sandro Bertolino ${ }^{b}$, José Antonio Gil-Delgado ${ }^{a}$ \\ a Cavanilles Institute of Biodiversity and Evolutionary Biology, University of Valencia, \\ Polígono La Coma s/n, 46980 Paterna (Valencia), Spain \\ b Department of Agricultural, Forest and Food Sciences, University of Turin, Largo Paolo \\ Braccini, 2, 10095 Grugliasco (Turin), Italy \\ * Corresponding author: avido2@uv.es
}

\begin{abstract}
Communal nesting has been described in many rodents including some dormouse species. In this study, we report the existence of this reproductive strategy in the garden dormouse Eliomys quercinus. Data was recorded by checking natural nests and nestboxes from 2003 to 2013 in SE Spain. Pups and adults dormice found in nests were captured and marked. Overall, 198 nests were found: $161(81.31 \%)$ were singular nests and $37(18.69 \%)$ were communal nests. Communal nests were composed by different combinations of one up to three females together with one up to three different size litters. The number of communal nests varied from year to year in accordance with the number of singular nests and no seasonal differences were observed. In at least one case, an adult female and her adult daughter were found sharing the same nest-box. The hypothesis that communal nesting was encouraged by a lack of favourable nesting sites was rejected. Litters protection from predators or conspecifics seems the most likely hypothesis to explain communal nesting in our garden dormouse population.
\end{abstract}

Keywords: Breeding; Dormice; Nest-box; Orange grove; Reproduction; Spain

\section{Introduction}

For many rodent (order Rodentia) species, communal nesting represents an opportunity to cooperate, live, breed and raise litters communally in order to share the parental effort with others members of the group (Gittleman, 1985; Jennions and Macdonald, 1994; Solomon and Getz, 1997). However, although this reproductive strategy has been extensively described for different families inhabiting a wide range of ecosystems (see Hayes, 2000), it remains unclear which could be the adaptive advantage for individuals to associate in the same nest (Ebensperger et al., 2007; Manning et al., 1995). Several studies have argued that these reproductive associations can provide the nesting group with some immediate fitness advantages such as cooperative foraging, allogrooming, defence against predators and other conspecifics or enhancing thermoregulation; other indirect benefits related to philopatric relationships have also been proposed as well (Ebensperger, 2001; Gilchrist, 2007; Gittleman, 1985). On the other hand, important costs have also been attributed to this nest aggregation, including resource competition, increased vulnerability to predation and increased parasite load and risk of infanticide (Hayes, 2000; König, 1997). Consequently, unravelling the ecological factors driving, and the consequences of, communal nesting in different species and under various ecological conditions is necessary in order to improve our knowledge of the benefits and costs linked to this reproductive strategy (Franco et al., 2011). Among dormice (Family Gliridae) communal nesting has been previously described in the fat dormouse Glis glis 
(Pilastro, 1992), the common dormouse Muscardinus avellanarius (Bright et al., 2006; Morris, 2004), and the woodland dormouse Graphiurus murinus (Madikiza et al., 2011). In the fat dormouse, co-nesting females were shown to be close kin (Marin and Pilastro, 1994), with younger communal nesters giving birth several days earlier than solitary breeders, allowing their progeny to reach a heavier weight before hibernation (Pilastro et al., 1996). However, pup predation presumably caused by the older female towards the younger's litter, was occasionally recorded. The garden dormouse Eliomys quercinus is a hibernating medium size rodent endemic to Europe where it shows a surprising adaptability to different environmental conditions, ranging from cold and wet forests to warm and dry plains and from Mediterranean habitats up to the tree line in the Alps (Bertolino et al., 2008, 2014; Moreno, 2002; Storch, 1978a). The limited information available on its nesting behaviour describes the species as a solitary nester, though associations between at least two adults have been documented occasionally in cold habitats (Baudoin, 1980; Bertolino and Cordero di Montezemolo 2007). The aim of this paper is to report the existence of communal nesting between garden dormouse females and evaluate the potential adaptative reasons of this behaviour.

\section{Materials and methods}

\subsection{Study area}

The study was carried out in an intensive orange tree plot of $16.92 \mathrm{ha}$, located in Sagunto, Valencia, Spain ( $39^{\circ} 42^{\prime} \mathrm{N}, 0^{\circ} 15^{\prime} \mathrm{W}, 30 \mathrm{~m}$ a.s.I.) near the Mediterranean coast, where orange plantations are widespread (Zaragoza, 1988). The climate is Mediterranean with mild winters and temperatures that normally do not drop below $5{ }^{\circ} \mathrm{C}$, and mean annual precipitation of about $350 \mathrm{~mm}$ (Ninyerola et al., 2005). Further information on the study area and the history of the dormouse population can be found elsewhere (Gil-Delgado et al., 2005). In this Mediterranean area the garden dormouse does not enter hibernation and females can reproduce all year long (Gil-Delgado et al., 2006).

\subsection{Methods}

Our protocol included two different methods. From 2003 to 2013, trees were inspected every 10-12 days from the last week of February to the first week of August coinciding with the bird breeding season for the presence of bird and dormouse natural nests, which when found were monitored every three days (Gil-Delgado et al., 2005). Additionally, since 2005, 40-60 wood nest boxes (dimensions: $14 \times 14 \times 20 \mathrm{~cm} ; 30 \mathrm{~mm}$ entrance hole diameter) were distributed randomly in the study area. Nest boxes were checked at least once per month throughout the year during daytime, recording its contents. All dormice found into the nest boxes were taken with gloves and forceps, placed into a plastic bottle and weighed with an electronic balance (accuracy $0.1 \mathrm{~g}$ ) although some adult females managed to escape during the capture proceeding. Dormice were then aged according to their weight and fur colour with an approximation to the nearest week of birth and classified in three different categories: adults (more than $60 \mathrm{~g}$ ), juveniles (between 45 and $60 \mathrm{~g}$ ) and cubs (less than $45 \mathrm{~g}$ ) (Palacios, 1974; Abad,1987). Cubs without hair were weighed directly without the help of forceps and plastic bottles. All dormice heavier than $10 \mathrm{~g}$ were provided with individual marks in a different way during two consecutive periods. During 2005, all juvenile and adult dormice were marked using individual coloured plastic collars, whereas pups were marked with different patterns of ear cuts. Then, from January 2009 to January 2013, all the individuals were marked using a unique numbered ear tag (National Band and Tag model 1005-1, Newport, KY, USA). No dormouse was ever anesthetized and after manipulation all the individuals were returned to their nest boxes. Our handling protocols followed the guidelines approved by 
the American Society of Mammalogists (Gannon et al., 2007). A nest was considered as "communal" when one or more litters were being reared within a single nest by two or more females or when two or more litters were sharing the same nest (Hayes, 2000). On contrary a single nest was composed by only one female rearing a single litter. On some occasions, some nests contained a numerous group of cubs of similar size and weight together with one or two females making impossible to differentiate the exact number of pups per litter. In this case, we considered these groups as a communal nest with parturition synchronicity when the number of pups was higher than 10 . This limit was established according to the theoretical maximum number of pups per litter in rodents and the highest litter size found in singular nests in our population (Gilbert, 1986; Viñals et al., 2012).

\subsection{Statistical analyses}

We tested the annual variation between the number of singular and communal nests with a Pearson's correlation test; data were square root transformed to achieve normality. Secondly, the seasonal variation in the number of communal nests was evaluated by a Chi-square test of Independence. Finally, we compared the average weight of females from communal and singular nests with a t-test. All statistical analyses were carried out using the SPSS statistical package, v.14.0 (SPSS Inc., Chicago, IL, USA).

\section{Results}

During the study 198 nests were found on trees or inside nest boxes: 161 (81.3\%) were singular nests, while $37(18.7 \%)$ were communal nests. Thus, dormouse females raised their offspring regularly alone but occasionally more than one female shared the same nest with two or rarely three different groups of cubs. Among communal nests, the number of different groups of cubs per nest varied between one and three and the number of adult females found in the nest varied also between one and three (see Table 1). The proportion of communal nests varied between 0 and $32 \%$ of the total nests per year; singular and communal nests showed a similar temporal trend $(r=0.75, P<0.05)$, with a clear increase during 2004 and 2005 and a decrease afterwards (Figure 1). Among the 37 communal nests, the relatedness degree between co-nesting females could not be generally established. However, in one single instance, two lactating females previously tagged, a mother and her daughter were found sharing the same nest-box. Communal nests were found in all seasons with a peak in summer and a decrease in the following seasons (Figure 2). However, the relationship between singular and communal nests and season was statistically weak $\left(\chi^{2}=6.72 ;\right.$ d.f. $\left.=3 ; P=0.073\right)$.

The weight of communal females varied between $63-103 \mathrm{~g}$ (mean $78.7 \pm 10.7 \mathrm{~g}$, $\mathrm{N}=24$ ), while females of singular nests varied between $64-96 \mathrm{~g}$ (mean $81.8 \pm 13.8 \mathrm{~g}, \mathrm{~N}$ $=22$ ), but no significant differences occurred (t-test; $t=0.84 ; P>0.1)$.

\section{Discussion}

Our results provide the first evidence of communal nesting in a garden dormouse population. According to our observations, dormouse females raised their offspring regularly in singular nests but occasionally more than one female shared the same nest with two or rarely three different groups of cubs. In some cases, however, we could not ensure that the different groups of cubs found in a nest-box belonged to different mothers because only one female was found inside during controls. In these cases, more adult females using the nest-box could have been absent during regular checks, but it could also be possible that some groups of cubs with different weight found in the same nest- 
box corresponded to two consecutive litters of a single mother. This fact could be explained since garden dormouse females can breed twice in a year in southern Europe (Palacios, 1974; Moreno, 1988; Viñals et al., 2012) and pregnant females can still be nursing their previous litters (Bussy, 1975; Abad, 1987). For other communal nests, our marking protocols allowed us to record and track the composition of the groups. In 2005, we recorded four females giving birth solitarily that subsequently engaged their litters in the same nest-box in different paired combinations. In addition, in 2013 a communal nest was found with two lactating adults (a mother and a daughter previously tagged) with two different groups of cubs. A temporal analysis of our data revealed that the occurrence of communal nesting events in our area varied considerably during the study period. This result is in agreement with Pilastro (1996), who also found an important variation in the yearly number of fat dormouse communal nests in the Italian Alps. In our study however, the number of communal nests fluctuated in accordance with the number of total nests, suggesting that this gregariousness did not occur by chance and that some ecological constraints should induce dormouse females to nest communally (Hayes, 2000). For instance, the lack of nest sites has been proposed as a potential factor driving communal nesting in dormice (Kahmann, 1965; Santini, 1978; Storch, 1978b; Vietinghoff-Riesch, 1960). Our study area was an orange grove composed by relatively young trees without natural holes, though nest-boxes could offer an artificial replacement. Communal nests could be considered as a response to the lack of natural or artificial nesting places only if all or most of the nest-boxes were occupied by dormice or other species, hence reducing the availability of nest sites for other female dormice. Throughout the study period, monthly nest-boxes occupancy rate was lower than $25 \%$ on average (range $0-$ $44.7 \%$ ) and natural nests, built under ground or between branches, or even bird nests (Tamarit et al., 2012), were used by garden dormice as well, meaning that nest site availability could not be considered a limiting factor (Pilastro, 1992). Another reason why females may nest communally is litter protection from predators and other conspecifics (Hayes, 2000; Pilastro, 1992). Dormice have not usually been detected as a common prey for many predators, due to their nocturnal habits and relatively low densities, but infanticide events may be possible in natural populations (Wolff, 1997). The pups remain inside the nest during their first months of life and they are therefore protected from largesize predators that cannot enter the nest (Valentin and Baudoin, 1980). However, females must leave their litters with no protection when feeding and during these periods the pups become vulnerable to small and medium size predators as black rats (Rattus rattus) and weasels (Mustela nivalis) able to enter inside the nest-box. As response to these attacks, communally nesting females could take turns in leaving the nests or may work together in nest defense from small predators or adult conspecifics (Ebensperger, 1998). Territorial behaviour has been suggested in garden dormouse females during gestation and lactation, when they could defend aggressively their litters from other females (Baudoin, 1980; Bertolino et al., 2001).

According to this, females engaged in a communal nest would suppress infanticide, probably as a result of their parental bond (Manning et al., 1995). In this situation, kin selection could be a determinant reason to explain the adaptative value of communal nesting in the garden dormouse as was proposed for other dormouse species (Marin and Pilastro, 1994). Considering that only a proportion of dormice nested communally, a dependence upon kin selection may indicate that a few related adult females were present in the study area at any one time. This could depend on a short life span in dormice, a high mortality rate due to predators, or a high long-distance dispersal of daughters to establish their own territories. Survival and life span in dormice are generally high in respect to non-hibernating species of similar body mass due to hibernation that helps to overcome the worst season and reduces yearly activity and energy demand (Turbill et al., 2011; Bieber et al., 2014).). For this reason, it would be expected that our Mediterranean non hibernating population show a lower survival rate in comparison to other hibernating populations of dormice (Schaub \& VaterlausSchlegel, 2001; Gil-Delgado et al. 2006; Amori et al., 2015, ). These differences could be 
based on the increase in the mortality, due to a higher impact of predators in this simplified habitat or to the costs associated to the prolonged reproductive season, although other causes such as variations in dispersal or changes in social composition of populations could also be involved (Bertolino et al., 2001; Pilastro et al., 2003; Turbill et al., 2011). Clearly, further investigations are needed to identify the fitness implications of communal nesting in the garden dormouse; in this respect, the comparison of data on survival and dispersal can be helpful.

\section{Acknowledgements}

We thank Tania Bazán, Jaime Gómez and Carmen Vives-Ferrándiz for field assistance and Zoë Gumm for revising the English text. We also wish to thank the anonymous reviewers for their suggestions. This research did not receive any specific grant from funding agencies in the public, commercial, or not-for-profit sectors.

\section{References}

Abad, P.L., 1987. Biología y ecología del lirón careto (Eliomys quercinus) en León. Ecología 1, 153-159.

Amori, G., Bertolino, S., Masciola, S., Moreno, S., Palomo, J., Rotondo, C., Luiselli, L. 2016. Aspects of demography in three distinct populations of garden dormouse, Eliomys quercinus, across Italy and Spain. Rendiconti Lincei, 27, 357-368.

Baudoin, C., 1980. Organisation sociale et communications intraspécifiques d'un hibernant : étude éthoécologique du lérot, Eliomys quercinus L. en Franche-Comté. BSc thesis, University of Franche-Comté, 1.

Bertolino, S., Viano, C., Currado, I., 2001. Population dynamics, breeding patterns and spatial use of the garden dormouse (Eliomys quercinus) in an Alpine habitat. J. Zool. 253, 513-521.

Bertolino, S., Cordero di Montezemolo, N., 2007. Garden dormouse (Eliomys quercinus) nest site selection in an alpine habitat. Ethol. Ecol. Evol. 19, 51-60.

Bertolino, S., Amori, G., Henttonen, H., Zagorodnyuk, I., Zima, J., Juškaitis, R., Meinig, H., Kryštufek, B., 2008. Eliomys quercinus. (Version 2014.2.). The IUCN Red List of Threatened Species.

Bertolino, S., Girardello, M., Amori, G., 2014. Identifying conservation priorities when data are scanty: a case study with small mammals in Italy. Mamm. Biol. 79, 349-356.

Bieber, C., Lebl, K., Stalder, G., Geiser, F., Ruf, T., 2014. Body mass dependent use of hibernation: why not prolong the active season, if they can? Functional Ecology, 28, 167-177.

Bright, P., Morris, P., Mitchell-Jones, A.J., 2006. The Dormouse Conservation Handbook. 2nd ed. English Nature, Peterborough.

Bussy, J., 1975. Deux parturition, dont une à nidation différée chez une femelle de lérot Eliomys quercinus, au cours du deuxième trimestre de l'année. Bull. Mens. Soc. Linn. Lyon 44, 296,329

Ebensperger, L.A., 1998. Strategies and counterstrategies to infanticide in mammals. Biol. Rev. 73, 321-346.

Ebensperger, L.A., 2001. A review of the evolutionary causes of rodent group-living. Acta Theriol. 46, 115-144. 
Ebensperger, L.A., Hurtado, M.J., León, C., 2007. An experimental examination of the consequences of communal versus solitary breeding on maternal condition and the early postnatal growth and survival of degu, Octodon degus, pups. Anim. Behav. 73, 185-194.

Franco, M., Quijano, A., Soto-Gamboa, M., 2011. Communal nesting, activity patterns, and population characteristics in the near-threatened monito del monte, Dromiciops gliroides. J. Mammal. 92, 994-1004.

Gannon, W.L., Sikes, R.S., The Animal Care, Use Committee of the American Society of Mammalogists., 2007. Guidelines of the American society of mammalogists for the use of wild animals in research. J. Mammal. 88, 809-823.

Gil-Delgado, J.A., Marco, E., Paredes, M., Vives-Ferrándiz, C., 2005. Seasonal clutch size variation of multi-brooded bird species: comparisons between breeding season and latitudes. Ibis 147, 206-212.

Gil-Delgado, J.A., Cabaret, P., Declercq, S., Gómez, J., Sánchez, I., 2006. Winter reproduction of Eliomys quercinus (Rodentia) in the orange groves of Sagunto (Valencia, Spain). Mammalia 70, 76-79.

Gilbert, A.N., 1986. Mammary number and litter size in Rodentia: The "one-half rule". Proc. Natl. Acad. Sci. USA 83, 4828-4830.

Gilchrist, J.S., 2007. Cooperative behaviour in cooperative breeders: costs, benefits, and communal breeding. Behav. Processes 76, 100-105.

Gittleman, J.L., 1985. Functions of communal care in mammals, in: Greenwood, P.J., Harvey, P.H., Slatkin, M. (Eds.), Evolution: Essays in honour of John Maynard Smith, Cambridge University Press, Cambridge, pp. 187-205.

Hayes, L.D., 2000. To nest communally or not to nest communally: a review of rodent communal nesting and nursing. Anim. Behav. 59, 677-688.

Jennions, M.D., Macdonald, D.W., 1994. Cooperative breeding in mammals. Trends Ecol. Evol. 9, 89-93.

Kahmann, H., 1965. Le loir (Glis glis L. 1776) dans les monts Gargano Italie (Apulie). Mammalia 29, 72-94.

König, B., 1997. Cooperative care of young in mammals. Naturwissenschaften 84, 95104.

Madikiza, Z.J.K., Bertolino, S., Do Linh San, E., 2011. Female in space, or female in space and time? First data on the socio-spatial organization and mating system of the woodland dormouse (Graphiurus murinus). J. Ethol. 29, 375-380.

Manning, C.J., Dewsbury, D.A., Wakeland, E.K., Potts, W.K., 1995. Communal nesting and communal nursing in house mice, Mus musculus domesticus. Anim. Behav. 50, 741-751.

Marin, G., Pilastro, A., 1994. Communally breeding dormice, Glis glis, are close kin. Anim. Behav. 47, 1485-1487.

Moreno, S., 1988. Reproduction of Garden Dormouse Eliomys quercinus lusitanicus, in southwest Spain. Mammalia 52, 401-408.

Moreno, S., 2002. Eliomys quercinus (Linaeus, 1766). Lirón careto, in: Palomo, L.J., Gisbert, J., (Eds.). Atlas de los mamíferos terrestres de España. Dirección general de la conservación de la naturaleza-SECEM-SECEMU, Madrid, pp. 432-435.

Morris, P., 2004. Dormice. British natural history series Stowmarket: Whittet Books, Suffolk.

Ninyerola, M., Pons, X., Roure, J.M., 2005. Atlas Climático Digital de la Península lbérica. Metodología y aplicaciones en bioclimatología y geobotánica. Universidad Autónoma de Barcelona, Bellaterra.

Palacios, F., 1974. Contribución al estudio de la biología y ecología del Lirón Careto, Eliomys quercinus Linnaeus 1766, en Iberia Central, Parte I: Crecimiento, Reproducción y Nidificación. Doñana Acta Vertebrata 1, 171-231.

Pilastro, A., 1992. Communal nesting between breeding females in a free-living population of fat dormouse (Glis glis L.). Boll. Zool. 59, 63-68. 
Pilastro, A., Missiaglia, E., Marin, G., 1996. Age-related reproductive success in solitarily and communally nesting female dormice (Glis glis). J. Zool. 239, 601-608.

Pilastro, A., Tavecchia, G., Marin, G., 2003. Long living and reproduction skipping in the fat dormouse. Ecology, 84, 1784-1792.

Santini, L., 1978. Biology, damage, and control of edible dormouse (Glis glis L.) in Central Italy, in: Proceedings of the Eighth Vertebrate Pest Conference, Sacramento, California, pp. 78-84.

Schaub, M., Vaterlaus-Schlegel, C. 2001. Annual and seasonal variation of survival rates in the garden dormouse (Eliomys quercinus). J. Zool. 255, 89-96.

Solomon, N.G., Getz, L.L., 1997. Examination of alternative hypotheses for cooperative breeding in rodents, in: Solomon, N.G., French, J.A. (Eds.). Cooperative Breeding in Mammals. Cambridge University Press, New York, pp. 199-230.

Storch, G., 1978a. Eliomys quercinus (Linnaeus, 1766) - Gartenschläfer, in: Niethammer,J., Krapp, F., (Eds.). Handbuch der Säugetiere Europas Band 1. Rodentia I (Sciuridae, Castoridae, Gliridae, Muridae). Akademische Verlagsgesellschaft, Wiesbaden, pp. 208-225.

Storch, G., 1978b. Glis glis (Linnaeus, 1766) - Siebenschläfer, in: Niethammer,J., Krapp, F. (Eds.). Handbuch der Säugetiere Europas Band 1. Rodentia I (Sciuridae, Castoridae, Gliridae, Muridae). Akademische Verlagsgesellschaft, Wiesbaden, pp. 243-258.

Tamarit, R., Viñals, A., Gil-Delgado, J.A., 2012. Use of blackbird nests as a resource by garden dormice (Eliomys quercinus). Peckiana 8, 135-140.

Turbill, C., Bieber, C., Ruf, T. 2011. Hibernation is associated with increased survival and the evolution of slow life histories among mammals. Proc. R. Soc. B 278, 33553363

Valentin, S., Baudoin, C., 1980. Ontogenèse du comportement du lérot, Eliomys quercinus L. (Rodentia, Gliridae). I. Développement corporel et moteur. Mammalia 44, 283-298.

Vietinghoff-Riesch, A., 1960. Der Siebenschläfers (Glis glis L.). Monographien der Wildsäugetiere 14, VEB Gustav Fischer Verlag, Jena.

Viñals, A., Bazán, T., Gil-Delgado, J. A., Gómez, J., 2012. No evidence for seasonal litter size variation in a Mediterranean garden dormouse (Eliomys quercinus Linnaeus 1766) population. Mammalia 76, 77-80.

Wolff, J.O., 1997. Population regulation in mammals: an evolutionary perspective. J. Anim. Ecol. 66, 1-13.

Zaragoza, S. 1988. Pasado y presente de la citricultura española. Consellería de Agricultura y Pesca, Generalitat Valenciana, Valencia. 
Table 1. Number of garden dormouse communal nests according to the number of adults and number of litters.

\begin{tabular}{|c|c|cccc|c|}
\cline { 3 - 7 } \multicolumn{2}{c|}{} & \multicolumn{5}{c|}{ Number of adult females in communal nest } \\
\cline { 3 - 7 } \multicolumn{2}{c|}{} & no adult & $\begin{array}{c}\text { one } \\
\text { adult }\end{array}$ & $\begin{array}{c}\text { two } \\
\text { adults }\end{array}$ & $\begin{array}{c}\text { three } \\
\text { adults }\end{array}$ & Total \\
\hline \multirow{2}{*}{$\begin{array}{c}\text { Number of } \\
\text { groups in } \\
\text { communal } \\
\text { nest }\end{array}$} & one group & 0 & $3^{1}$ & 6 & 0 & $9^{2}$ \\
& two groups & 4 & 9 & 7 & 1 & 21 \\
\cline { 2 - 7 } & three groups & 1 & 3 & 2 & 1 & 7 \\
\hline
\end{tabular}

${ }^{1}$ despite the presence of a single female these nests containing more than 10 pups were considered composed by more than one litter

${ }^{2}$ the number of singular litters could not be determined in these nests

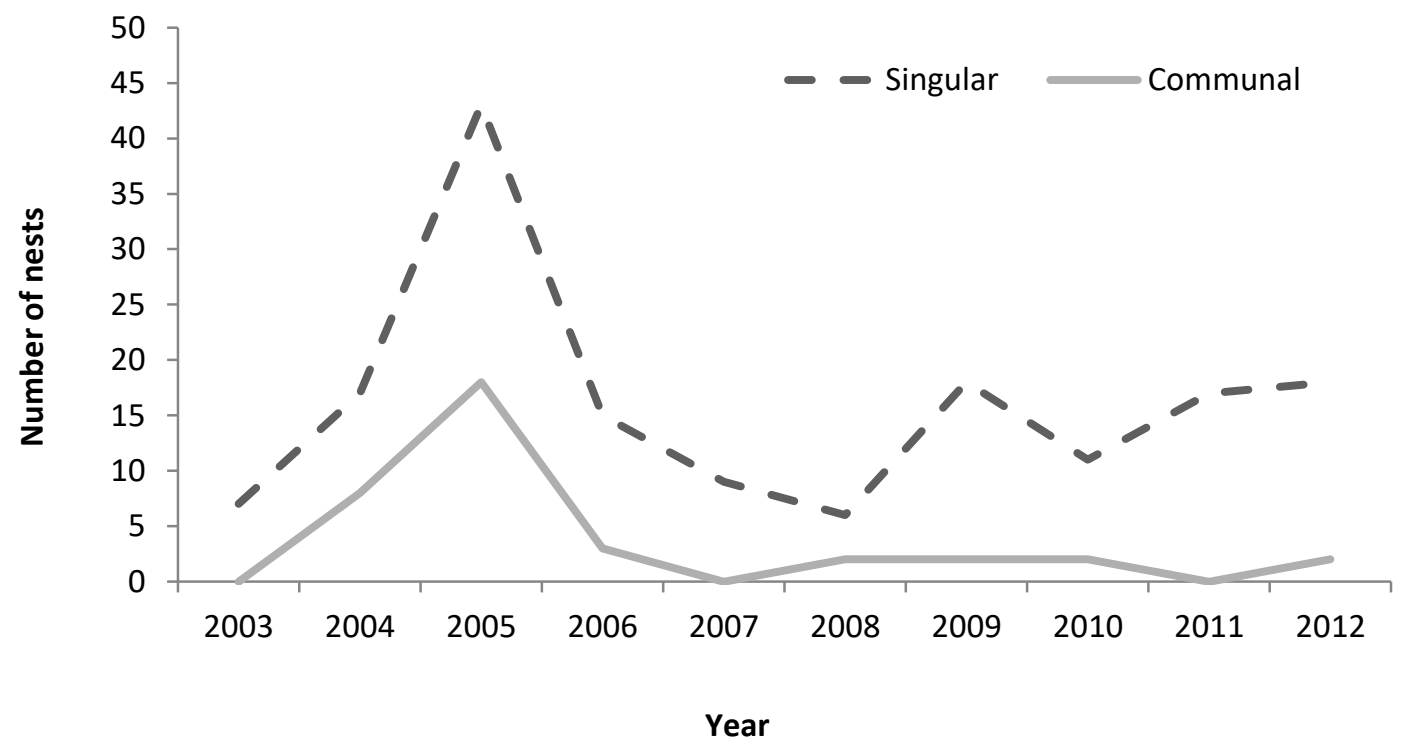

Figure 1. Annual variation in the number of singular and communal litters of garden dormouse 


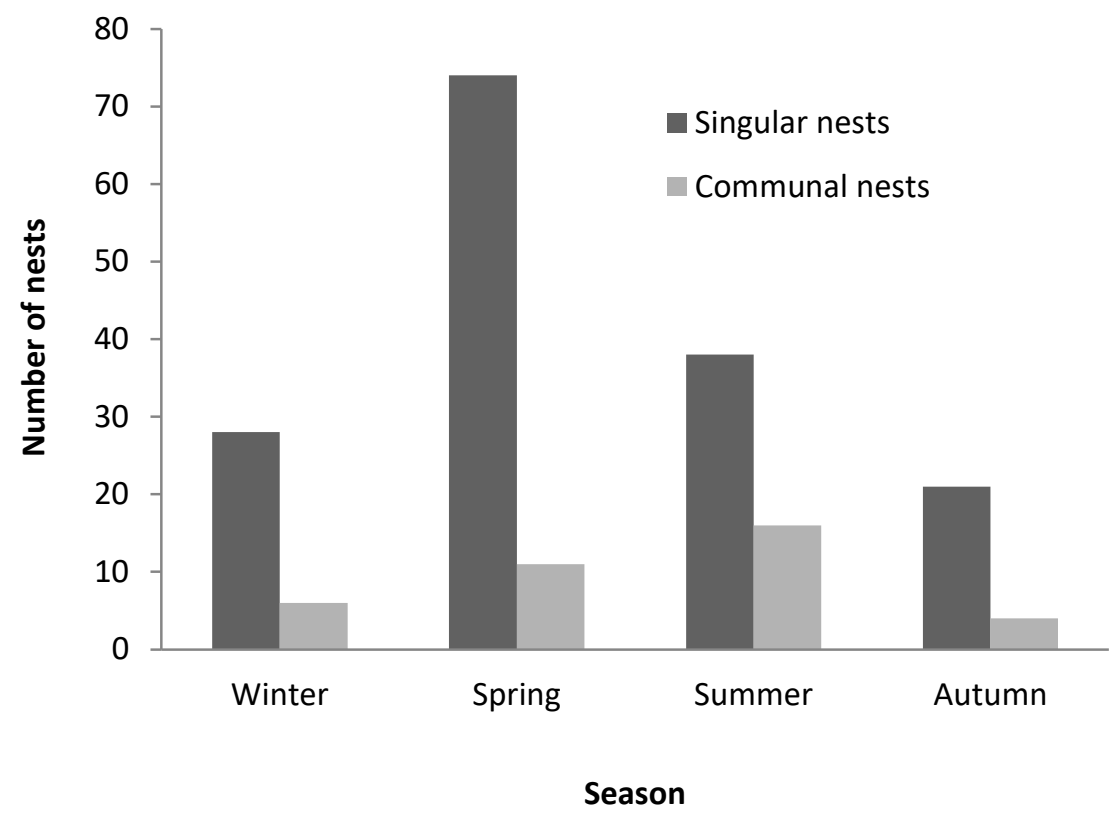

Figure 2. Seasonal number of singular and communal litters of garden dormouse 